\title{
O FINAL DA VIDA NO SÉCULO XXI
}

\author{
Alda Britto da Motta
}

\section{INTRODUÇÃO}

0

0 que é a sociedade deste início do século XXI?

Predominantemente capitalista, global, planetária em sua comunicação e interação política, extremadamente desigual nas relações de poder entre países e, em cada um destes, entre as (pessoas de) diferentes classes sociais. "Pós-industrial" e predominantemente de serviços, mas ao mesmo tempo em aceleração tecnológica produtiva e circulatória de comunicações e mercadorias em compasso difícil de acompanhar. No terreno das relações sociais, a grande revolução se deu a partir do século XX, na denúncia da extrema desigualdade das relações de gênero, luta política desencadeada pelas mulheres no movimento feminista, que continua e se propaga até os dias de hoje.

E como se relacionam, neste "mundo" em mudança, as gerações?

São também relações de poder, realizando-se em uma complexidade e dinamismo incessantes; complexidade pelo grande número e pela novidade de relações e conteúdos afetivos envolvidos - entre solidariedades e conflitos - e dinamismo, porque as relações entre gerações constituem-se em dimensão das relações sociais em que se forjam privilegiadamente as mudanças sociais. São gerações que vivenciam, mais do que nunca - e enunciando à maneira de Mannheim (1928) - este tempo social como uma "não contemporaneidade de contemporâneos". Isto é, são gerações que, mesmo contemporâneas, não têm as mesmas experiências e trajetórias de vida. Pois, também como já analisara Mannheim, "o mesmo tempo" não é igual para todos. Tanto mais,

${ }^{1}$ Professora e Pesquisadora da Pós-Graduação em Ciências Sociais e do Núcleo de Estudos Interdisciplinares sobre a Mulher (NEIM) da Universidade Federal da Bahia, Brasil. aldamotta01@hotmail.com 
analisamos hoje, que elas são formadas também por experiências de gênero, classe e etnia.

Efetivamente, o século XXI contempla um panorama inusitado de idades, em amplitude e em largueza. Como efeito direto de um processo crescente de longevidade, tem-se a coexistência, em toda parte, de numerosos grupos etários, a ponto de as famílias contarem com a frequente simultaneidade de quatro a cinco gerações, em que, não raro, duas são de idosos, principalmente de idosas. Ao mesmo tempo, registra-se a extensão crescente dos anos de vida dos indivíduos, até para além dos cem anos; levando a outra extensão, desta vez terminológica, de supercentenários, para designar os maiores de cento e dez anos.

Torna-se importante fazer um inventário mais acurado dos elementos desse quadro da vida social atual, e uma análise avaliativa dos recursos instituídos pela sociedade para lidar com eles, assim como as respostas dos idosos a esses recursos disponibilizados. Que informação realmente se tem para além de uma atomizada e frequentemente falseada discussão sobre "a questão da Previdência" e os "perigos" que o crescente número de aposentadorias e pensões, a serem pagas pelo Estado, representa para a reprodução social?! Ou, por que o grande número de idosos com suas propaladas doenças crônicas também seria uma ameaça, desta vez, à manutenção ou sobrevivência do sistema público de saúde? E ainda, se os "benefícios" proporcionados pelo Estado aos mais velhos seriam mesmo tão superiores àqueles destinados às crianças e aos jovens a ponto de instituir, com isso, uma situação de iniquidade geracional?

Mais além de um discurso público sem sentimentos sobre a velhice, importa avaliar o que há de intolerância ou manobra política nele, o que reforça ou amplia o já conhecido preconceito que campeia na vida cotidiana e, sobretudo, que recursos sociais e existenciais para esta fase da vida realmente existem e qual a sua eficácia. Importa, igualmente, conhecer-se a capacidade de resposta, pessoal e coletiva desses homens e mulheres idosos às frequentemente inóspitas condições sociais que se apresentam à realidade da sua vida.

Para tentar contribuir neste sentido, pretendeu-se um dossiê que contenha informações e análises sobre algumas das condições sociais mais amplas ou abarcantes que contextualizem a vida atual dos idosos e algumas das suas respostas a elas. Entre estas, já se podendo registrar a extensão extra-família da sociabilidade, através dos grupos de "terceira idade"; a participação no mercado de trabalho como destruição de fronteiras entre atividade e aposentadoria, inclusive esta como marco de velhice e sugestão de recolhimento; e, não por último, a transformação de idosos em atores políticos.

Não houve propostas - de certo modo esperado - de textos sobre a morte para este dossiê, apesar de predominar o distanciamento dela na sociedade contemporânea. A 
morte como horizonte dos velhos, e questão que seria remetida apenas a esses indivíduos, sempre postos à margem do percurso social oficial, não é mais um problema só dos velhos - os jovens também "chegam ao fim". Principalmente, e cada vez mais, pela violência.

\section{O CORPO VELHO}

Em um momento da vida social em que se conjuga longevidade e centralidade consumista sobre o corpo, todos os grupos de idade são convocados para um proclamado aprimoramento do físico e da saúde; rosto sem marcas (rugas e manchas), corpo magro e musculoso, barriga "de tanquinho", "ajuda" da indústria de silicone e de um saber médico "atualizado". Juvenilização / mercantilização do corpo que termina por atingir com peso especial o segmento da sociedade em processo de envelhecimento; sobretudo as mulheres, interessadas em estar "jovens", bonitas e sempre "em forma".

Diante da batuta simultânea do discurso médico e midiático sobre 0 "envelhecimento saudável", todos são compelidos a harmonizar suas ações ou aquiescências a um receituário em prol de uma alimentação "balanceada" e da realização de exercícios físicos, de preferência assistidos por profissionais, para manterem-se ativos e joviais. Uma inflexão especial neste sentido é posta sobre os mais velhos que chegam a ser culpabilizados, pessoal e socialmente - seja quando exercem sua plena autonomia e resistem aos apelos do receituário, seja por precariedade da condição de classe - por "descuidarem-se da saúde". Esta injunção social vem sendo criticada por alguns setores mais esclarecidos da saúde coletiva e por cientistas sociais voltados para a área do envelhecimento, em especial Guita Debert, que cunhou a expressão "reprivatização da velhice", retomada em recente trabalho:

A dissolução dos problemas da velhice avançada nas representações gratificantes da terceira idade produz um processo que tenho chamado de "reprivatização da velhice" e que envolve sua transformação numa responsabilidade individual (um problema de consumidores falhos que não souberam se envolver em atividades motivadoras e adotar formas de consumo e estilos de vida capazes de retardar o envelhecimento) ou num problema das famílias e, enquanto tal, pode desaparecer do leque de preocupações sociais. (DEBERT, 2012, p. 218).

Isto é, ameaça despolitizar-se a questão, com a consequente exclusão do idoso como um sujeito de direitos.

Neste dossiê, vamos encontrar uma postura também crítica das ações e prescrições no campo da saúde, por caminhos e dimensões de análise diferenciadas: um 
no plano epistemológico e o outro no terreno da prática cotidiana de profissionais, como nos textos aqui publicados de Monique Borba Cerqueira e de Márcia Andrade e Mónica Franch.

Monique Cerqueira ecoa denúncias sobre o biopoder, mostrando, ao mesmo tempo, a ênfase na responsabilidade do indivíduo sobre sua saúde e, também, a despolitização dessa questão. Tangencia a crítica cultural atual à obrigação de se estar sempre "bem" e "feliz", analisando as conseqüências das injunções do saber médico e consumista de produtos e serviços na vida cotidiana. A autora endossa a crítica de Coelho e Fonseca (2007) à afirmação de que em uma "vida saudável", "a dor e o sofrimento precisam ser banidos", são "0 avesso do viver"; como também se refere à direção oposta: "A ideologia da saúde e do corpo perfeito nos leva a contemplar as doenças que retorcem a figura humana como sinônimo de fracasso pessoal" (FOUCAULT, 2003), o que vai acontecer, supinamente, em direção aos mais velhos.

Analisando as políticas públicas, Cerqueira salienta como essa idéia do envelhecimento saudável vai repercutir na abordagem do envelhecimento ativo, preconizada pela OMS, ecoando no Brasil via planos de ação que promoveriam esse envelhecimento saudável e ativo. Mas, na avaliação de alguns desses programas, a autora aponta como evidência um distanciamento entre a população alvo e as práticas de saúde, com, inclusive, uma impossibilidade de diálogo entre a coletividade, sempre vista como uma totalidade homogênea, e o discurso de promoção da saúde sendo "inequivocamente prescritivo".

Monique Cerqueira toca ainda em um ponto chave: a redução dos custos da assistência em saúde como finalidade, para o qual os indivíduos são conduzidos a um comportamento de auto responsabilização por sua saúde, deixando margem à percepção de um diferencial de gênero. Os comportamentos saudáveis que implicitamente orientam ao rejuvenescimento como condição de aceitação e reinserção social constituem um terreno onde realmente transitam mais intensamente as mulheres, em cuja busca do corpo saudável está imersa também a histórica busca da beleza como legitimação de presença social.

Como parte importante da atual ênfase discursiva sobre o corpo, situa-se a sexualidade. Terreno movediço para todas as idades, porém com muito maior dificuldade e ambiguidade no caso dos mais idosos, principalmente para as mulheres, sempre mais "preservadas" ou socialmente contidas. Uma ambivalência que decorre, inclusive, da dificuldade de se concatenarem imagens sociais tão diferenciadas como a dos aclamados e mercadologicamente úteis idosos "ativos", "de terceira idade", e a dos mais velhos, já com perdas corporais, ou simplesmente encarnando uma tradicional e preconceituosa figura do passado, de "velhinhos" dependentes e "naturalmente" assexuados. Nos últimos decênios, uma relativa liberalização de visão já alcançada em 
relação à sexualidade dos idosos, propiciada pela ideia e por demonstrações públicas desse "envelhecimento ativo", facilitado pela ampla difusão do desenvolvimento da indústria farmacêutica - do viagra à reposição hormonal - passa a encantar menos quando começam a aumentar os registros de casos de AIDS em idosos. São velhos que não procuram "seu lugar".

Nessa contiguidade interativa entre sexualidade e outras expressões ou funções corporais, torna-se particularmente interessante analisar como são vistos e tratados os idosos em serviços de saúde. Foi o que fizeram Márcia Andrade e Mónica Franch, com irretocável pesquisa em uma unidade do Programa Saúde da Família, na Paraíba. Essas unidades institucionais - importantes programas do Sistema Único de Saúde (SUS) como já bem demonstrou Parry Scott (2006), segmentam a clientela por idades e consequentes prioridades de atenção no Programa, o que significa que tendo o Estado, proverbialmente, como foco de interesse a esfera da reprodução, isto é, o "binômio" mãe-filho, jovens e velhos ficam à margem, "justamente pela ambiguidade e dubiedade do seu papel na reprodução" (SCOTT, 2006, p.114). Ficam à margem especialmente os idosos, cuja vida reprodutiva já estaria encerrada, esperando-se que seus problemas sejam só de deterioração da saúde, como captaram estas autoras no dia-a-dia de acompanhamento na sua pesquisa no PSF.

Os indivíduos que completam 60 anos mudam de grupo de atenção e passam para um outro, específico, que cresce, porém com atendimento só em dias fixos e, talvez, em horários insuficientes; além de ser freqüentado principalmente por mulheres. Essa mudança traz outras consequências desvantajosas: com atendimento prioritário à hipertensão e diabetes, as mulheres deixam de ser alvo do programa de prevenção ao câncer de colo de útero. As pesquisadoras consideram que o fato de as mulheres, nessa faixa etária, serem excluídas do exame citológico pode se analisado em função da interpretação do Estado, que parece compreender que as mesmas encerraram não só seu ciclo reprodutivo, mas também sua vida sexual. Tal interpretação documenta a crítica que há muito venho fazendo (BRITTO DA MOTTA, 2011) às políticas etaristas do Estado, principalmente para as mulheres, em campanhas preventivas circunscritas às idades medianas, isto é, as reprodutivas.

As pesquisadoras constataram que idosas que procuram espontaneamente o posto para um exame citológico são atendidas, porém anotaram o comentário de uma enfermeira de que isto "é trabalhar de graça", pois o trabalho das profissionais deve atingir metas quantitativas, objeto de relatórios mensais, que não consideram esse tipo de demanda. A pesquisa demonstra como as restrições por idade se imbricam nos diferenciais de gênero. E embora aquelas avultem, há dentro delas uma restrição menor aos homens. Estes, como é amplamente sabido, frequentam menos as instituições de saúde, e quando aparecem no PSF têm, segundo relatam Andrade e Franch, um melhor acolhimento - pelo menos no que tange à sexualidade. Ao contrário da expectativa de 
"encerramento” em relação às mulheres, “... Os profissionais alimentam uma expectativa de que os homens prolonguem por mais tempo sua vida sexual, e que 0 façam com parceiras mais novas".

Enfim, a observação das autoras demonstra que apesar de tentar atender às diretrizes da OMS sobre a "velhice ativa" como sinônimo de qualidade de vida e redução de danos e gastos onerosos com saúde, "o PSF não incorpora a sexualidade idosa, que, no entanto, irrompe cotidianamente em forma de diversas e inesperadas demandas".

\section{HOSPITAIS: CUIDADO OU VIOLÊNCIA?}

Do serviço de saúde ao hospital, dá-se um passo gigante: da atenção simples ao cuidado às pessoas; da eventual vigilância à saúde a uma responsabilidade quase total pela saúde e até pela vida das pessoas. Mas, não há diferença perceptível nelas no que tange à (des)consideração aos velhos. 0 cotidiano em um hospital pode sumarizar a valoração que a sociedade abriga em relação a cada um dos grupos de idade que atende, não esquecendo também sua situação de classe: criança "esperança", mulheres sob atenção especial na fase reprodutiva, velhos que vão talvez para morrer... Locus onde cabem situações polares, do proverbial qualificativo "hospital clean" às nada raras "infecções hospitalares" de desfecho imprevisto. Microcosmo onde circulam diferentes tipos de profissionais, categorizados segundo uma hierarquia de status profissional, mas também de gênero.

Em um hospital da rede pública baiana, Andréa dos Santos Souza, Edméia Campos Meira e Maria do Rosário de Menezes realizaram uma pesquisa com o objetivo de identificar concepções e experiências dos trabalhadores da saúde sobre violência contra idosos em hospitais públicos e suas formas mais frequentes de manifestação. As autoras identificaram casos ou situações que são pertinentes de rotular como de violência institucional contra pessoas idosas. De logo, o encontro do fato repetido choca, até pela contradição à proposta dessas instituições, uma vez que a violência contra idosos em hospitais vai à contra-mao da missão dos mesmos: preservar e proteger a vida. Além do mais, o enfrentamento desse tipo de violência é prejudicado em função de a violência institucional ser vista como intrínseca aos serviços públicos de saúde dada a alta demanda e a precariedade de recursos materiais, humanos e da estrutura física.

As pesquisadoras, apoiadas na definição da Organização Mundial de Saúde de que a violência praticada contra pessoa idosa é "um ato (único ou repetido) ou omissão que lhe cause sofrimento, angústia e que se reproduz em qualquer relação na qual exista expectativa de confiança" (OMS, 2002), vão encontrar, no cotidiano das instituições de saúde, maus-tratos que se caracterizam pela omissão ou recusa de cuidados necessários (negligência), em especial àqueles com maior grau de dependência. 
Diversas categorias profissionais foram entrevistadas nesta pesquisa, embora não houve disponibilidade de médicos. 50\% dos entrevistados admitiram a existência de violência no cotidiano da instituição, percebendo nuances dela. No entanto, nenhum profissional se reconheceu como agente de violência - os maus tratos são sempre produzidos pelo outro. Somente um dos entrevistados que admitiu ter presenciado maus tratos relatou ter se posicionado em relação ao colega: "Pode deixar que eu faço, não precisa você cuidar, pode deixar que eu cuido". As pesquisadoras, também profissionais da saúde, analisam essas formas de violência - predominantemente negligência, omissão e discriminação - como resultantes da interação de múltiplos fatores vindos do idoso (frustrados na suas expectativas de encontrar alivio para seu sofrimento) e dos profissionais (que pensam agirem de acordo com as condições inadequadas e precárias de trabalho).

As autoras referem situações semelhantes reportadas em pesquisas em outros estados do país e também no Exterior. 0 que propicia remeter a um outro elemento comum, que as pesquisadoras também reconhecem: o preconceito contra os idosos, que parece sentimento universal.

\section{ProteÇÃo SOCIAL}

Quando a proteção social falha, ao ser autoimposta aos idosos e, em várias formas, negaceada nas instituições de saúde, há que ver-se outros caminhos, outras instâncias que podem significar, por sua vez, outras relações entre as gerações. Quem sabe, menos opressivas que estas. Restam os sistemas de aposentadoria (Previdência) e a Assistência Social que, pela Constituição de 1988, compõem, com a Saúde, a dimensão da Seguridade Social. No caso do envelhecimento e da instituição da aposentadoria, o sistema é claramente montado na noção de solidariedade pública entre as gerações: os trabalhadores na ativa contribuem para sustentar os inativos, que podem enfim, ou programaticamente, descansar nos seus aposentos... Socialmente são vistos como "dependentes", como o são também as crianças.

Curiosamente, enquanto a trajetória do sistema produtivo do capitalismo vai-se desenrolar em crises e reestruturações produtivas, precariedade do emprego e desemprego "estrutural", a posição geracional de dependentes na família vai ser passada aos mais jovens e chega-se ao quadro atual, agora alimentado também por outra grande mudança, uma certa reestruturação também das relações de família, com descasamentos, recasamentos ou novas solterices, e retornos de filhos à casa dos pais. (BRITTO DA MOTTA, 1998; 1999). Os idosos se mantêm no mercado de trabalho ou reingressam a ele, dividem proventos, pensões ou salários com filhos e netos. É uma proteção social inesperada, meio às avessas - o que Benedita Cabral (1997) cunhou como "relação inversa de cuidados" - tanto em termos da hierarquia tradicional, 
quanto às relações entre as gerações na família, como da transferência, para o âmbito desta, da proteção devida aos cidadãos pelo Estado, este em processo concomitante de orientação neoliberal.

Importante lembrar que quanto mais o Estado tenta reduzir a aposentadoria dos mais velhos, mais deixa desprotegida a família que eles, em grande parte, sustentam (MEDEIROS 1987). É sobre toda essa problemática que se debruçam Josimara Delgado, Cristiane Villa-Flor e Eulália Azevedo, tendo sempre no horizonte a percepção teórica de que estão tratando de relações entre gerações, e com um forte conteúdo de gênero. Delgado e Villa-Flor analisam a efetividade material das ações governamentais que predominantemente se desenham no papel, e Azevedo acompanha, na história brasileira e na atualidade, a reação política a essa desproteção dos aposentados, homens e mulheres, em movimento social. Delgado e Villa-Flor assinalam a já citada influência dos organismos internacionais na formulação de novas políticas para os idosos que remetem, e ao mesmo tempo absorvem, as representações sobre "terceira idade" - esta protagonizada pelos "idosos jovens" desde a década de 1960, conforme então instituído, atualizada em termos de envelhecimento ativo, ou saudável e velhice bem sucedida.

Tais condições, por sua vez (ou circularmente), serão cobradas aos idosos, instados a reinventar a sua velhice (DEBERT, 2012), como já foi comentado anteriormente. As pesquisadoras discutem essa divisão da responsabilidade de proteção social ao idoso com a família e a comunidade, na que as diversas políticas se pautam na vulnerabilidade, na exclusão e/ou na convivência, deixando de lado aspectos da vida material e simbólica dos idosos. 0 que, somada à sempre reiterada discussão política sobre os "perigos" deflagrados pelo envelhecimento populacional para a reprodução da sociedade, vão determinando um recuo da proteção social pública.

Por outro lado, Delgado e Villa-Flor assinalam a emergência de um direito social não contributivo, o Beneficio de Prestação Continuada, previsto na Política Nacional de Assistência Social, como um importante mecanismo de proteção à população mais velha, porém, ao mesmo tempo, sendo parte do crescimento da centralidade dos benefícios assistenciais. 0 que demanda novas e urgentes discussões sobre o retrocesso no campo dos direitos já concedidos, com "a contraposição entre direitos do trabalho e direitos assistenciais".

As autoras se detêm, ainda, com muita propriedade, sobre 0 envelhecimento feminino, "uma realidade bastante invisível para a produção acadêmica em geral" (e para o movimento social também, inclusive 0 feminista, lembre-se) que em mais uma instância, essa da proteção social, tem reproduzidas as desigualdades de gênero. A base empírica da pesquisa vai se situar sobre a verificação, na cidade do Salvador, da viabilização de uma 
série de serviços previstos na PNAS (Política Nacional de Assistência Social). A conclusão mais geral da mesma foi que os serviços não estavam se realizando de forma efetiva, com o ônus resultante da falta recaindo novamente sobre as mulheres, ainda aprisionadas a seus papéis tradicionais de gênero, especialmente 0 de cuidadoras.

Eulália Azevedo apresenta o ângulo de visão e ação do movimento social deflagrado pelos mais velhos - uma resposta política inesperada dos "velhinhos" aposentados às condições insatisfatórias de realização da proteção social. Para isso, historia as políticas governamentais de proteção social desde 0 início do século XX, assinalando como a pressão reivindicatória de várias categorias profissionais esteve presente, desde cedo, na sociedade brasileira. Detem-se sobre o momento de unificação do sistema previdenciário e a emergência de um "novo sindicalismo", diante do qual aposentados/as e pensionistas não se sentem contemplados/as e iniciam uma outra frente de luta, organizados/as em Associações, Federações e uma Confederação Nacional (COBAP). 0 desenrolar dessa luta é objeto de vários anos de pesquisa dessa autora, que faz aqui desfilar a transformação da atuação desses grupos de interesse em um movimento social mais amplo, com base identitária coletiva própria - "Somos a maior categoria do país" (SIMÕES, 1998) - e sua posterior mobilização mais ampla, em favor da Previdência Social Pública como um direito maior de cidadania que alcança toda a sociedade.

Teoricamente analisada enquanto relações entre gerações, mas com um forte componente de gênero, essa trajetória, inicialmente quase só masculina, é acompanhada na sua tensão pela efetividade da Seguridade Social, por uma Previdência Social Pública, até alcançar a promulgação do Estatuto do Idoso, em 2003. 0 trabalho documenta e analisa, ainda, o refluxo do movimento, mas também a persistência de algumas das suas iniciativas mais novas. Como em alguns estados do país, entre os quais o da Bahia, a criação de Fóruns Permanentes em Defesa do Idoso (e não apenas dos aposentados) assumiu um caráter pedagógico, de trabalho de conscientização política de grupos profissionais ou de lazer formados por idosos, estes compostos em maioria por mulheres, - estas já tendo, então, afluído plenamente ao movimento - tendo como principal orientação a divulgação e implementação do Estatuto do Idoso.

Diante das grandes perdas para os beneficiários com as reformas já realizadas na Previdência Social, a pesquisadora registra vários depoimentos dos que as sofreram, todos eles no sentido da apontar a magnitude dos percentuais e a dificuldade de equilibrar o orçamento doméstico. Ainda assim, a 
garantia de regularidade do recebimento da renda previdenciária assegura um mínimo de condições de sobrevivência. Não muito mais.

\section{Alternativas DE TRABALHO}

Outra importante resposta reativa de idosos e idosas às condições sociais adversas vem, como referido, pelo trabalho. Uns prolongam o tempo de permanência na ocupação já exercida, enquanto outros iniciam novas atividades laborais. Sentem que precisam continuar ativos porque o clima social propicia ou demanda isso, mas, principalmente, porque aposentadorias e pensões não preenchem 0 orçamento doméstico, ainda mais quando idosos são, cada vez mais, arrimos de família. Alguns, poucos, pensam no trabalho como auto-realização, se sua condição de classe permite essa alternativa. Neste dossiê, cinco textos analisam alternativas de trabalho de idosos ou com idosos, mas todos eles predominantemente orientados pela condição de gênero, fruto de pesquisas de Iracema Brandão Guimarães, Marisete Hoffmann-Horochovski, Giseli Gontarski e José Miguel Rasia, Helena Hirata e Cíntia Engel.

Iracema Brandão Guimarães inicia o texto explicitando a amplitude de possibilidades de realização postas hoje para as pessoas idosas, como 0 aumento do acesso ao consumo, a realização de antigos ou novos planos e também a permanência ou reingresso no mercado de trabalho.

A autora comenta como esse prolongamento da atividade produtiva já faz parte dos planos individuais das pessoas que estão envelhecendo e também, de certo modo, da programação das empresas, "ainda que muitas vezes sob o manto da terceirização e da precarização do trabalho". A partir de dados estatísticos confrontados com trabalho de campo, a pesquisadora vai perceber tendências principais de emprego ou de trabalho autônomo e os possíveis significados para as suas escolhas, guardadas as oportunidades ensejadas pela condição de classe e de gênero. Afirma, ainda, que nessas escolhas e/ou oportunidades predomina 0 trabalho por conta própria num universo heterogêneo no qual o trabalho autônomo constitui o maior espaço para os mais velhos. São atividades que permitem uma relativa autonomia e aproveitamento de anteriores habilidades, que se referem principalmente à construção civil, aos serviços domésticos e àquelas que exigem maior qualificação e se enquadram no setor de educação, saúde, serviços sociais, administração pública, etc. 
As velhas benzedeiras da pesquisa de Marisete Hoffmann-Horochovski representam uma outra prática. Um trabalho, em última análise, social, que busca e prolonga a tradição; prática ao mesmo tempo alternativa e de origem imemorial. Com uma forte marca de gênero, adquire também uma marca de idade: é um trabalho principalmente de velhas, pois as jovens urbanizadas atuais recusam esse aprendizado. É um artesanato "da alma", fadado talvez a desaparecer - apesar do seu conteúdo "religioso" -, assim como a da linda renda de bilro e outros trabalhos artesanais tradicionais populares, com raros aprendizes e escassa demanda.

Não há, entretanto, apenas tarefa de trabalho posta na benzeção: há também disposição mística incorporada, identificação ("É um dom") e prática ritual aplicada. Prática que adquire um sentido que ultrapassa muito 0 âmbito individual, para se constituir em uma relação com a comunidade, que nela confia, a procura e, portanto, a legitima. Narrativas das benzedeiras são recolhidas pela pesquisadora e o tom da sua entrega é repetido nos vários depoimentos que nos apresenta. A persistência das benzedeiras irá depender de uma atualização social, seja por iniciativa delas mesmas, identificando-se enquanto grupo atuante; seja por iniciativa do poder público, em termos de reconhecimento cultural. As duas alternativas, segundo reporta a pesquisadora, já se iniciam no Paraná.

0 trabalho de Giseli Gontarski e José Miguel Rasia traz a experiência de envelhecimento entre um grupo de moradores de Mafra (SC), observando o trabalho e a aposentadoria como experiências fundamentais na construção dos diversos significados da velhice. Os autores indicam que não há idade certa para o inicio da velhice, pois esta só pode ser pensada se estiver relacionada à condição do velho em relação às atividades cotidianas e às suas possibilidades de autonomia. Nesse sentido, o trabalho se coloca como condição objetiva para que os "velhos" vivam e reconstruam diariamente sua subjetividade.

Na pesquisa de campo, além da experiência de trabalho, são abordadas questões relativas a cotidiano dos "velhos", o desejo e a sexualidade. "0 desejo despertado no outro significa a continuidade das performances sociais", afirmam Gontarski e Rasia, destacando que a velhice não pode ser reduzida às perdas, ainda que esta seja a visão predominante nos discursos contemporâneos sobre envelhecimento. Neste trabalho se destaca a dissonância entre o discurso sobre velhice (que tradicionalmente se volta para a "morte social do individuo") e a experiência dos "velhos" nas suas práticas cotidianas, nas quais os autores observam vivencias plurais, indicando que há várias velhices possíveis, constituídas pelo contexto do qual eles fazem parte, mas também pelas trajetórias individuais que marcam a "subjetividade das experiências de envelhecimento". 
0 trabalho do cuidado é bem outro, exercido muito mais sobre idosos do que por idosos, embora se encontre cada vez mais, nestes tempos de longevidade crescente, idosos "jovens", principalmente mulheres, cuidando dos mais velhos - o fenômeno novo da atuação de uma geração pivô. Helena Hirata reporta resultados da pesquisa recente que realizou no Japão, país de alta população idosa e diante da crise econômica, onde o próprio Estado está estimulando o recrutamento e formação para o trabalho de cuidado. Faz, também, algumas comparações com a situação do "care" na França e no Brasil - por sua vez objetos de outra fase de pesquisa em realização, países onde esse incentivo do Estado não se apresenta.

0 trabalho do cuidado, como ocupação em crescimento e, talvez, profissionalizante, vai repor em cena a questão do contrato social de gênero. Realmente, a existência dessa atividade prestativa, via de regra de sentido intergeracional, abrangendo tarefas materiais informadas por considerações de ordem emocional e cada vez mais demandada, está se desenvolvendo no sentido de se constituir em campo profissional, o que pode significar remetendo à trajetória clássica da divisão sexual do trabalho - maior afluência de homens para onde há melhores oportunidades, em contraste com o fluxo histórico de presença maciça de mulheres na realização do cuidado. Helena Hirata comenta esta questão: "Há um paradoxo evidente nesse investimento feito pelos homens em tarefas consideradas tradicionalmente como femininas..." Mas, a autora termina por verificar que “... entre 0 nãoemprego ou o desemprego e o trabalho no setor do 'care', a escolha por parte dos homens é clara”. Relata com detalhes a situação específica do Japão quanto a esse recurso do Estado em uma economia em crise, ao patrocínio formativo de ex-trabalhadores desempregados como cuidadores. 0 que não é verificado na França, nem no Brasil.

Fica implicitamente também colocada a velha hierarquia da divisão sexual do trabalho, em que determinadas ocupações têm salários mais baixos - nada raro, as que são habitualmente exercidas por mulheres. Aqui, trata-se do caso, milenar, do cuidado. A pesquisadora reporta uma defasagem significativa entre o salário médio de um trabalhador masculino em geral e 0 de um homem empregado no "care". Este é apenas 63\% do salário médio daqueles, entretanto, consegue ser mais elevado do que o de trabalhadores do "care" na França e, principalmente, no Brasil.

Cintia Engel proporciona informação sobre as estratégias de cuidado doméstico e institucional, a partir de uma pesquisa realizada no DF e em Goiânia em mais de 25 Instituições de Longa Permanência para idosos/as. Engel faz contrapontos entre as 
alternativas institucionais, como vilas e "casas de abrigamento", que, segundo a mesma, variam pouco quanto à estrutura de organização do cuidado.

Basicamente, identifica a autora, há duas opções principais no local pesquisado: as "casas de abrigamento", nas quais há áreas comuns e quartos partilhados entre duas ou três pessoas e onde as práticas de cuidado (banho, alimentação) são mais intensas e regradas. A outra opção são as "casas-lares", organizadas em formato de vila e constituída por pequenas residências, nas quais os cuidados são mais esporádicos em função dos idosos terem condições de ser mais independentes, embora existam horários e regras institucionais que facilitam 0 trabalho das cuidadoras. A autora destaca a visão homogenizadora, um imaginário padronizado de perda de autonomia na velhice que parece organizar as atividades institucionalizadas do cuidado do idoso que, mesmo nas vilas, nas quais haveria uma maior independência dos idosos, ao se tratar de questões como a sexualidade e o manejo do dinheiro da aposentadoria, há "privacidade vigiada e comedida".

Dialogando com o artigo de Hirata neste dossiê, interessa destacar que as cuidadoras que Engel identifica na sua pesquisa, geralmente, têm curso técnico de enfermagem ou realizaram cursos rápidos e específicos para o cuidado de idosos, e recebem baixos salários por esta atividade. Esta atividade é desenvolvida, na sua grande maioria, por mulheres que trazem a experiência de cuidado com a criação de filhos ou, especifica de cuidado de familiares idosos.

Todavia, a pesar do preparo técnico e/ou da experiência que habilita estas profissionais, as mesmas manifestaram que não deixariam seus familiares idosos a disposição dos cuidados institucionais, reproduzindo a ideia acerca das Instituições de Longa Permanência como local de abandono. A autora conclui que o impasse do cuidado familiar está nas dificuldades das famílias darem conta de políticas baseadas em modelos ideais de espaço doméstico, sendo que o cuidado recai especialmente nas mulheres, algumas das quais devem se afastar do mercado de trabalho ou reduzir 0 tempo de trabalho remunerado para ter mais tempo disponível para o trabalho doméstico. A autora também destaca as políticas familistas, nas quais se partilha 0 cuidado de idosos entre família, Estado e mercado, embora tais iniciativas partilhadas ainda são escassas no Brasil. 0 impasse das Instituições de Longa Permanência, para Engel, estaria no visão negativa das mesmas, para o qual é míster a quebra da visão das mesmas como opção para os idosos sem família.

Por fim, a família teria que aparecer aqui. Fosse há dez ou mais anos atrás, vários "papers" sobre a temática certamente teriam sido propostos para este dossiê, ainda expressando descobertas e inquietações diante de mudanças muito rápidas, ou radicais, que então se processavam. Foi o momento em que analisei essas transformações, "... porque as relações entre os gêneros e as 
gerações estão-se realizando em novas formas e segundo outros códigos. Casamento, criação de filhos, separações, exercício da sexualidade, chefias, composição do orçamento doméstico, solidariedades e responsabilidades intergeracionais, quase nada está sendo o mesmo". (BRITT0 DA MOTTA, 1998, p. 13).

Naquela época, discutia-se uma "crise" da família, calcada principalmente no que parecia ser o declínio da instituição do casamento, diante de um ritmo novo de descasamentos, recasamentos e recomposições de famílias - em verdade, o surgimento de novos modelos de família esboçados pela dinâmica da vida social e propiciados, sobretudo, pelas novas relações de gênero (inspiradas pelo feminismo) e entre as gerações. Também era considerada estranha a referência à "família do idoso", no que apenas se começava a discernir o novo papel de provedores dos mais velhos (BRITTO DA MOTTA, 1998, p. 72).

Em 2012 aquelas configurações já estão mais claramente definidas, especialmente essa centralidade dos mais velhos como apoio fundamental na família. Vai nesta direção a exposição de Nívea Santana e Isabel Maria Lima, que combinam dados censitários e pesquisas de natureza qualitativa para tentarem discernir como está esse idoso, "cada vez mais presente no convívio social". Através de interessante recurso metodológico, articulando dados quanti e quali, as pesquisadoras buscam documentar a dimensão da relação de apoio e provisão dos mais velhos aos mais jovens, inclusive, o leque de possibilidades desses apoios. Além dos frutos da permanência ou do retorno ao mercado de trabalho - recurso sabidamente próprio do idoso brasileiro - e do benefício previdenciário, lembram as pesquisadoras, citando Neves (2006), as avós protetoras (são principalmente as mulheres, sabemos), conseguem aglutinar mais alguns recursos, com o acesso a bolsas de alimentos e a posse ou aluguel de moradia, sem esquecer a produção doméstica.

Evidentemente, nem todos conseguem isso e a precariedade é a que mais comumente dá o tom da vida dessas famílias de idosos e idosas. Mais pesquisas são necessárias sobre os seus modos de vida, inclusive na modalidade alternativa, porém mais e mais encontrada, em que se dá uma espécie de troca ou deslocamento de papéis quando, na ausência real ou consentida da geração dos pais, as avós maternam os seus netos. 


\section{AINDA A VIOLÊNCIA}

No Brasil se discute intensamente a questão da violência, sua incidência crescente, as variadas formas de realização, objetos predominantes de vitimização e projetos de coibi-la ou diminuir a sua incidência. Pesquisados seus modos de realização no passado, não resta dúvida, como realidade social, que a violência no Brasil é uma maneira cotidiana e implicitamente aceita de resolução de conflitos (ADORNO; CARDIA, 1999).

Entretanto, uma de suas modalidades, a violência contra os idosos, ainda é uma temática relativamente pouco analisada, se comparada à atenção nesse sentido dada a outros segmentos geracionais. Ao mesmo tempo, ela é portadora de uma multiplicidade de enfoques ou de significações. Discutida como realizando-se alternativamente em dois âmbitos distintos, o públicoinstitucional (desde as baixas aposentadorias aos maus tratos em instituições de longa permanência) e o doméstico-familial (e nas denúncias aparecendo muito mais este âmbito e personagens), como relata Faleiros (2009), e Guita Grin Debert e Amanda Marquês de Oliveira, neste dossiê. Em função dessas pequisas, poder-se-ía também pensar a existência de coincidência frequente das duas formas/âmbitos, sendo a institucional (a exemplo da relatada neste dossiê por Andréa Santos Souza et al.) sempre obscurecida pela escassez de denúncias.

Aliás, seria possível ir mais adiante e pensar a própria posição marginal do idoso no fluxo das relações sociais definidas como importantes, como uma condição de perene submissão à violência. Também as discussões teóricas ainda são inconclusivas, apesar da transformação da velhice em questão social. A violência contra o segmento social idoso é expressão direta das relações de poder entre as gerações, imersas em um contexto forte de relações de gênero. Mas, não se costuma discutí-la assim. Nem no âmbito geral da teoria sociológica, nem no âmbito teórico/político da discussão feminista (BRITT0 DA MOTTA, 2010), certamente não por coincidência, duas dimensões temáticas de análise que via de regra não alcançam as relações entre as gerações.

Por outro lado, quando vistos os casos na prática, apontam Debert e Oliveira a partir de suas pesquisas, a tendência é a de feminizar as vítimas em sua "fragilidade", mesmo que se trate de homens; e a de familiarizar as causas do crime, atribuindo-as a falhas nas relações entre os membros da família. Isto é reforçado pelo fato de que nas denúncias policiais os familiares dos idosos apareçam como maioria entre os perpetradores do abuso. Isso, paralelo à tendência atual do crescimento da interferência do Estado nas 
relações mais pessoais e cotidianas dos indivíduos em sua vida social, e até nas relações privadas de família, que está levando ao risco de que essas delegacias de proteção ao idoso sejam transformadas em instâncias encarregadas da judicialização das relações sociais. As autoras concluem apontando para o risco de responsabilizar a família pela destituição humana, e, ainda, transformá-la em alvo da ação policial e da ausência de reconhecimento dos direitos de minorias.

Por fim, esperamos que os textos deste dossiê contribuam para o debate sobre as reais possibilidades de participação social da pessoa idosa, o quanto ela tem sido marginalizada e sobre as possibilidades de real apoio e cuidado ao final da vida.

\section{REFERÊNCIAS}

ADORNO, Sérgio; CARDIA, Nancy. Dilemas do controle democrático da violência: execuções sumárias e grupos de extermínio. In: TAVARES DOS SANTOS, José Vicente (Org.). Violência em tempo de globalização. São Paulo: Hucitec, 1999, p.66-99.

BRITTO DA MOTTA, Alda. As Velhas Também. Revista ex aequo, Porto, n. 23, Ed. Afrontamento/APEM, p.13-21, 2011.

. Aproximações teóricas em análises de relações de gênero e entre as gerações: 0 caso das violências contra a mulher idosa. In: BURITY, Joanildo A.; RODRIGUES, Cibele Maria L.; SECUNDINO, Marcondes de A. (Orgs.). Desigualdades e Justiça Social:

Diferenças Culturais \& Políticas de Identidade. v. 2. Belo Horizonte: Argvmentvm, 2010, p.85-102.

"Não tá morto quem peleia": A pedagogia inesperada nos grupos de idosos. Tese de doutorado, Programa de Pós-Graduação em Educação, Universidade Federal da Bahia, 1999.

Introdução ao Dossiê Gênero, Família e Fases do Ciclo de Vida. Caderno CRH, Salvador, n. 29, jul-dez., 1998.

CABRAL, Benedita. A vida começa todo dia. Revista de Estudos Feministas, Rio de Janeiro, v. 5, n. 1, p.104-192, 1997.

DEBERT, Guita Grin. Imigrantes, Estado e Família: o cuidado do idoso e suas vicissitudes. In HIRATA, Helena; GUIMARÃES, Nadya A. Cuidado e Cuidadoras. As várias faces do trabalho do care. São Paulo: Ed. Atlas, 2012.

FALEIROS, Vicente de Paula. Violência contra a pessoa idosa no Brasil. In: LIMA, Fausto Rodrigues; SANTOS, Claudiene (Orgs.). Violência domestica (vulnerabilidade e desafios 
na intervenção criminal e multidisciplinar). Rio de Janeiro: Lúmen Júris, 2009, p.231242.

FOUCAULT, Michel. História da Sexualidade, vol. 1. A Vontade do Saber. Rio de Janeiro: Graal, 2003.

MANNHEIM, Karl. 0 problema das gerações. In: Sociologia do Conbecimento. Porto, Portugal: Res Editora, [s.d.]. p. 115-176.(Edição original: 1928).

MEDEIROS, Marcelo. A importância dos rendimentos dos idosos nos rendimentos das famílias. In: CAMARANO, Ana Amélia (Ed.). Como vai? População brasileira. Brasília, v. 3, n. 3, dez., 1987.

ORGANIZAÇÃO MUNDIAL DE SAÚDE. World Report on Violence and Health. Genebra: WHO, 2002.

SCOTT, Parry. Gerações, Comunidade e o Programa Saúde da Família: reprodução, disciplina e a simplificação administrativa. In: LINS DE BARROS, Myriam. (Org.) Familias e Gerações. Rio de Janeiro: Editora FGV, 2006.

SIMÕES, Júlio Assis. A maior categoria do país: o aposentado como ator político. In: LINS DE BARROS, Myriam (Org.). Velhice ou Terceira Idade. Rio de Janeiro: Fundação Getúlio Vargas, 1998. p.13-34. 